\title{
Prevalence and determinants of childhood diarrhoea among graduated households, in rural area of Shebedino district, Southern Ethiopia, 2013
}

\author{
Alemu Tamiso ${ }^{1}$, Mezgebu Yitayal ${ }^{2}$, Akilew Awoke ${ }^{2}$ \\ ${ }^{1}$ Departments of public health, Unit of epidemiology and biostatistics, Arba Minch University, Arba Minch, Ethiopia \\ ${ }^{2}$ Institute of public health, Departments of epidemiology and biostatistics/health management and health economics, University of \\ Gondar, Ethiopia
}

\section{Email address:}

alemutamiso@yahoo.com (A. Tamiso), akilew24@gmail.com (A. Awoke), mezgebuy@gmail.com (M. Yitayal)

\section{To cite this article:}

Alemu Tamiso, Mezgebu Yitayal, Akilew Awoke. Prevalence and Determinants of Childhood Diarrhoea among Graduated Households, in Rural Area of Shebedino District, Southern Ethiopia, 2013. Science Journal of Public Health. Vol. 2, No. 3, 2014 , pp. $243-251$.

doi: $10.11648 /$ j.sjph.20140203.28

\begin{abstract}
Background: Despite dramatic declines in deaths due to diarrheal disease among infants and children in developing countries, diarrhea remains a significant cause of morbidity and mortality. Even though Rota vaccine is not available to decrease morbidity and mortality due to diarrheal disease, Ethiopian government endorsed health extension program at 2004 and through it, the country was increasing latrine coverage and utilization, creating positive behavioral change in household level regarding personal hygiene and environmental sanitation to decrease the morbidity due to diarrhea, even though diarrhea remains second common cause of under-five mortality in the country. So the aim of the study was to assess the prevalence and determinants of childhood diarrhea among graduated households in rural area of Shebedino district, Southern Ethiopia. Methods: A community based cross-sectional study was carried out in April 2013. A multi -stage sampling to reach household and systematic random sampling technique was used to select 769 graduated households that had at least one under-five children. Data were collected using a pre-tested and structured questionnaire by trained nurses. Bivariate and hierarchical logistic regression analyses were undertaken to identify determinant of childhood diarrhea. Results: Seven hundred sixty nine households were enrolled in the study making a response rate of $98.8 \%$. The prevalence of childhood diarrhea was found to be $19.6 \%,(95 \%$ CI: $(16.8,22.4)$. The household graduated before 2003 EC ([AOR: 1.83, 95\% CI (1.16, $2.89)$, two or more under five children [AOR: 1.96, 95\% CI $(1.23,3.12)]$, history of maternal diarrheal morbidity [AOR: 5.76, 95\% CI:(3.50, 9.47)], mode of feeding by cup[AOR:2.13,95\%CI:(1.09, 4.13)], and malnutrition [AOR:4.06,95\% CI :(2.54-6.50)]were determinants of childhood diarrhea. Conclusion: Prevalence of childhood diarrhea was high. Time of household graduation, kebeles, and maternal diarrheal illness, mode of feeding and nutritional status were determinants of childhood diarrhea. Refreshing the graduated households on minimum of every two years and health extension program should focus on child care practice to prevent and control childhood diarrhea.
\end{abstract}

Keywords: Childhood Diarrhea, Graduated Household, Health Extension Program, Hierarchical Logistic-Model, Ethiopia

\section{Introduction}

Though figurative declines in deaths due to diarrheal disease among infants and children in developing countries, diarrhea remains a significant cause of morbidity and mortality(1). The disease causes 1.87 million under five deaths globally. World Health Organization (WHO) African and South-East Asia Regions combined contain 78\% (1.46 million) of all diarrhoea deaths occurring among children in the developing world. Sub- Saharan Africa is the region, where highest rates of child mortality were reported, where one in eight children dies before age five. This is more than 17 times the average for developed regions ( 1 in 143)(2). According to community based report and survey, diarrhea is second common cause of under-five mortality (88 per 1000 live births), and morbidity (13\%) in Ethiopia(3).

The cause of child mortality and morbidity in developing countries is multi-factorial. Interaction of socio-demographic, 
environmental, and behavioral factors influences the occurrence of childhood diarrhea morbidity(4-7).

Comparisons over time of the global burden of diarrheal diseases have revealed secular trends and demonstrated the impact of public health interventions(1). Therefore ministry of health of Ethiopia boldly endorsed health extension program (HEP) in 2004 with the aim of capitalization of active community's participation in their health affairs; to give emphasis to action based health message deliveries to bring about positive change in health behavior of individuals and communities and to initiate a practical implementation of some of the concepts and components of Primary Health Care(8-10). The country strives to achieve this strategy by making households graduated through health education about the way of prevention and control of diarrheal disease. Graduated households are households included in the Health Extension Program(HEP) and graduated after 96 hours of training on the 16 basic health extension package elements(10).

By improving the latrine coverage and utilization, maternal health and child care practice through HEP, Ethiopian government further strengthens diarrhea prevention and control effort. However, the status of graduated households after intervention was not assessed, particularly in the households graduated previously(9).

Thus, this study assessed the prevalence and determinants of childhood diarrhea among graduated households in rural area of Shebedino district, southern Ethiopia.

\section{Methods}

\subsection{Study Design, Area and Population}

A community-based cross-sectional study was conducted in Shebedino district in April 2013. All graduated households with mothers/care takers who have under-five children and randomly selected graduated households with under-five children in selected kebeles were the source and study populations, respectively. The District has 3 urban and 32 rural kebeles (the smallest administration unit in Ethiopia). The district has one district hospital, nine health centers and 35 health posts.

\subsection{Sample Size and Sampling Procedure}

EPI INFO version 7.1.0 was used to calculate the sample size using single population proportion formula based on an assumption that $18 \%$ of the under five children had two-week prevalence of diarrhea in other part of Ethiopia; with marginal error of $4 \%$, a standard score corresponding to $95 \%$ certainty, design effect of 2 , accounted for two-stage sampling. The calculated total sample size was 778 graduated households that had at least one under-five child. A two-staged sampling procedure was employed, first by selecting six Kebeles from the 32 by using lottery method, and systematic sampling (every $9^{\text {th }}$ households) was used to select study households, In case, where there were more than one under-five children in the same household, index child was selected by lottery method to collect information on child's health characteristics, The first household interviewed was identified by a modified random walk method and if no mother/care taker or under five child is available in the selected household, the next nearest household was included in the survey.

\subsection{Data Collection Methods and Quality}

Pretested and structured questionnaire was prepared based on reviewed literature and used to collect variables like socio-demographic characteristics of both the child and the parents, , time of household graduation, environmental factors(type of water source, distance to water source, daily water consumption, availability of latrine and function of latrine and refuse handling), behavioral(hand washing, method of water storage, method of water drawing, feeding practice and duration of breast feeding and malnutrition) and nutritional related characteristics). Data were collected by six diploma nurses who were trained for this purpose, under the supervision of two public health professionals and the investigators.

\subsection{OTerms}

Diarrhea: The presence of diarrhea (three and more loose or liquid stools per day) among under-five children in the house within two weeks period prior to survey, as reported by the mother or care taker was considered as childhood diarrhea.

Index child: refers to a child who was included in the study from a household to have Information on the demographic and health characteristics, and also to calculate the prevalence of diarrhea.

Wealth quintiles: constructed by asking the presence or absence of durable assets at the household level by giving a score of 1 if present and score of 0 if absent. The asset mean scores were re-categorized into five different wealth quintiles of equal proportion (Lowest, Second, Middle, Fourth and Highest wealth quintile groups.

Time of household graduation: Graduated household were classified in two groups by categorizing the household graduated 2000EC, 2001EC and $2002 \mathrm{EC}$ as before 2003EC and 2003EC and $2004 \mathrm{EC}$ as after 2003EC.

\subsection{Data Analysis}

Data were coded manually, entered and cleaned using EPI-INFO version 7.1.0 and exported to SPSS version 20 for analyses. Frequencies, proportions and measures of central tendency were used to describe the study subjects. The necessary assumption of the logistic regression model was checked by Hosmer \& Leme show's goodness of fit test statistics ( $p$-value=0.846). Bivariable and Hierarchical logistic regression technique was used to assess the relative effect of the explanatory variables. Variables reached a p-value less than 0.3 were kept in the subsequent analyses. The results were presented using crude odds ratio (COR), adjusted odds ratio (AOR) and confidence intervals $(95 \%$ 
CI). In all analyses, $P<0.05$ were considered as a significant.

\subsection{Ethical Considerations}

Ethical clearance was obtained from the institutional review board of the University of Gondar. Informed' verbal consent was obtained from mothers/ care takers after informing them about the objectives of the study. Confidentiality of the information was assured from all the data collectors and investigators. The questionnaire was administered anonymously, locked with keys (hard copy) and password protected (soft copy). Children, who were found to have diarrhea during data collection, were given Oral Rehydration Salt and severe cases were advised to consult the nearby health facility for better management

Table 1. Socio demographic characteristics of the study graduated household in rural area of Shebedino district, 2013.

\begin{tabular}{|c|c|c|}
\hline Variables & Frequency & $\%$ \\
\hline \multicolumn{3}{|c|}{ No of person in graduated household } \\
\hline $1-3$ & 135 & 17.5 \\
\hline $4-6$ & 435 & 56.6 \\
\hline$>=7$ & 199 & 25.8 \\
\hline Total & 769 & 100 \\
\hline \multicolumn{3}{|l|}{ Age of the mother } \\
\hline $15-24$ & 314 & 40.8 \\
\hline $25-34$ & 315 & 41.0 \\
\hline$>35$ & 91 & 11.8 \\
\hline Don't know her age & 49 & 6.4 \\
\hline Total & 769 & 100 \\
\hline \multicolumn{3}{|l|}{ Religion } \\
\hline Protestant & 669 & 87.0 \\
\hline Orthodox & 25 & 3.3 \\
\hline Muslim & 62 & 8.1 \\
\hline Catholic & 13 & 1.7 \\
\hline Total & 769 & 100 \\
\hline \multicolumn{3}{|l|}{ Ethnic group } \\
\hline Sidama & 725 & 94.3 \\
\hline Others & 44 & 5.7 \\
\hline Total & 769 & 100 \\
\hline \multicolumn{3}{|l|}{ Maternal education } \\
\hline No education & 358 & 46.6 \\
\hline Primary education & 360 & 46.8 \\
\hline Secondary-education and Above & 51 & 6.6 \\
\hline Total & 769 & 100 \\
\hline \multicolumn{3}{|l|}{$\begin{array}{l}\text { No of under-five children in } \\
\text { Graduated households }\end{array}$} \\
\hline One & 503 & 65.4 \\
\hline Two and more & 266 & 34.5 \\
\hline Total & 769 & 100 \\
\hline \multicolumn{3}{|l|}{ Wealth index quintal } \\
\hline Lowest & 82 & 10.7 \\
\hline Second & 324 & 42.1 \\
\hline Middle & 248 & 32.2 \\
\hline Fourth & 89 & 11.6 \\
\hline Highest & 26 & 3.6 \\
\hline Total & 769 & 100 \\
\hline \multicolumn{3}{|l|}{ Time of household graduation } \\
\hline Before 2003 EC & 308 & 40.1 \\
\hline After $2003 \mathrm{EC}$ & 461 & 59.9 \\
\hline Total & 769 & 100 \\
\hline
\end{tabular}

\section{Result}

\subsection{Socio-Demographic Characteristics}

Seven hundred sixty nine households with at least one under-five children were enrolled in the study making a response rate of $98.8 \% .81 .8 \%$ of the mothers were below the age of 35 years and $97 \%$ were married, about $87 \%$ protestant, 94.1\% Sidama by ethnicity, $88.3 \%$ house wife, and $46.6 \%$ having no formal education. Of the $411(53.4 \%)$ who attended formal education, 347(45.1\%) attended some primary education.

Five hundred thirty eight $(70 \%)$ of fathers engaged in farming and $52 \%$ of them attended primary education. About $74 \%$ of the graduated households had less than 7 people in their families and there was only one under-five children in 503(65.4\%) graduated household. Five hundred sixty four $(73.3 \%)$ participants perceived themselves as having average economic status, compared to their neighbour. Fifty nine point nine percents of households were graduated after 2003 E.C. regarding wealth index quintal, $324(42.1 \%)$ were in the second wealth quintile.

\subsection{Environmental Characteristics}

About 59\% had grass roofed houses with more than three rooms. More than half $(60.7 \%)$ of rural household had houses with mud floor, and $25.9 \%$ of the households kept cattle in their houses. All households surveyed had privately owned latrine, and (99.4\%) of the households utilize the latrine, but feces were observed around the pit hole in only $17.3 \%$ of the households.

Three hundred seventy (47.9\%) of graduated households disposed the refuse in open field; 399 (\%) of households disposed refuse either in the pit or by burning.

Five hundred forty eight (71.3\%) households used pipe as the main source of Water. A good proportion of households $(26.5 \%)$ also used protected well as main source of drinking water. Regarding distance to water source, 333 (43.3\%) households used to get water in a 15 minutes walking distance from their home. The mean per capita per day water consumption in graduated household was $33.82 \pm 13.3$ liters. The majority (97.8\%) of household used to fetch water from its source to household by covered materials. Ninety two percents of households used jerry can as water collection material.

\subsection{Behavioral and Child Demographic and Health Characteristics}

More than three fourth $(86.6 \%)$ of mothers/caretakers in graduated household feed their child supplementary food in addition to the breast milk and of the total 769 mothers/caretakers, $85(11.1 \%)$ mothers breastfed their children exclusively. $41.5 \%$ of mothers in graduated household breastfed their child for two years or more. Out of the total 679 mothers/caretakers who started supplementary feeding for their children $72(8.7 \%)$ started before the child reached 6 months, and $607(78.7 \%)$ after the age of 6 
months (Table 3 ). From seventy eight point seven mothers started supplementary feeding after the age of 6 months, Only $6(0.8 \%)$ bottle-fed their children and majority of mothers/care givers $(62.3 \%)$ used their hands to feed their child.

Five hundred thirty six (69.7\%) respondents mentioned the importance of latrine for prevention of excreta borne disease and few (3\%) mentioned for aesthetic purpose.

Regarding the knowledge on flies as cause of disease, 93.6\% respondents felt that they had knowledge that flies can transmit disease, and $67.8 \%$ of them responded that diarrhea could be caused by flies.

Of the total interviewed mothers/caretakers, $677(88 \%)$ of them used to cover their water storage container at the time of the survey, and $720(93.6 \%)$ claimed that they drew water from a storage container by pouring.

Three hundred eighty four (49.9\%) of index children were in the age group twenty four months and above and $395(51.4 \%)$ of index children were males. Two hundred thirty $(29.9 \%$ ) children in were born either fourth or beyond, and $150(19.5 \%)$ were first born (Table 4$)$. Four hundred sixty nine $(61.0 \%)$ of children were delivered in health institutions, and $621(80.8 \%)$ of index child were immunized for measles.

Forty nine point nine percents of Children (384) were in the age group two years and above group. Two hundred twenty three (29\%) children were confronted with nutritional problem.

\subsection{Prevalence of Childhood Diarrhea}

The prevalence of childhood diarrhea was $19.6(95 \% \mathrm{CI}$ $(16.8,22.4))$. The major proportions of diarrhea mentioned were watery (15.8\%) and the rest was bloody or mucus type $(3.7 \%)$.

\subsection{Determinants of Childhood Diarrhea: Bivariable Results}

\subsubsection{Socio Demographic Determinant}

Time of household graduation[COR: $2.13,95 \% \mathrm{CI}:(1.49$, $3.06)$ ], number of under five children[COR:1.46, 95\% CI:(1.02, 2.12)] and the selected Kebeles (Telamo [COR: 1.90, 95\% CI:(1.03, 3.52)], Dobe toga [COR:3.14, 95\% CI:(1.68, 5.86)] were significantly associated with prevalence of childhood diarrhea in bivariable analysis of socio-demographic variables

\subsubsection{Environmental Determinants}

Mean per capita water consumption [COR:0.98, 95\% CI: $(0.96,0.99)]$, type of roof [COR:2.68, 95\% CI: $(1.79,4.03)]$ and floor materials[COR:2.64, 95\% CI: (1.74, 3.99)], distance from water source to house[COR:1.54, 95\% CI: $(1.05,2.27)]$, and household where livestock live together with human being[COR:1.93, 95\% CI: $(1.26,2.95)$ were significant.

\subsubsection{Behavioral and Child Health and Demographic Determinants}

In Bivariable analysis of behavioral and child health and demographic variables; Maternal diarrheal morbidity [COR: $5.00,95 \%$ CI: $(3.38,7.39)]$, age of index child [COR: 0.48, 95\% CI: $(0.25,0.93)]$, the place where index child borne(COR: $1.59,95 \% \mathrm{CI}:(1.09,2.33)]$, and nutritional status[COR: 3.364, 95\%CI: $\quad(2.326,4.866)]$, were significantly associated with childhood diarrheal morbidity.

Table 2. Behavioral and child care practice determinants in relation to childhood diarrhea among graduated household in Shebedino District, Southern Ethiopia, 2013

\begin{tabular}{|c|c|c|c|}
\hline \multirow[t]{2}{*}{ Variables } & \multicolumn{2}{|c|}{$\begin{array}{c}\text { Childhood diarrhea } \\
\text { N (\%) } \\
\end{array}$} & \multirow[t]{2}{*}{ COR ( $95 \% \mathrm{CI})$} \\
\hline & Yes & No & \\
\hline \multicolumn{4}{|c|}{ Hand washing after the use of toilet. } \\
\hline Yes & $106(18.4)$ & $471(81.6)$ & 1 \\
\hline No & $45(23.4)$ & $147(76.6)$ & $1.36(.917-2.019)$ \\
\hline \multicolumn{4}{|c|}{ Separate can to take drinking water from the container. } \\
\hline Yes & $131(19.8)$ & $529(80.2)$ & 1 \\
\hline No & $20(18.3)$ & $89(81.7)$ & $0.907(.539-1.528)$ \\
\hline \multicolumn{4}{|c|}{ Drinking storage container has a cover. } \\
\hline Yes & $128(18.9)$ & $549(81.1)$ & 1 \\
\hline No & $23(25.0)$ & $69(75.0)$ & $1.43(.859-2.38)$ \\
\hline \multicolumn{4}{|c|}{ The mode of taking drinking water from storage container } \\
\hline Pouring & 141(19.6) & $579(80.4)$ & 1 \\
\hline Dipping & $10(20.4)$ & $39(79.6)$ & $1.053(.513-2.16)$ \\
\hline \multicolumn{4}{|c|}{ Did excreta of children can be cause of disease } \\
\hline Yes & $145(19.6)$ & $596(80.4)$ & 1 \\
\hline No & $6(21.4)$ & $22(78.6)$ & $1.12(0.45-2.82)$ \\
\hline \multicolumn{4}{|c|}{ Maternal history of diarrhea } \\
\hline Yes & $69(43.7)$ & $89(56.3)$ & $5.00(3.38-7.39)^{* *}$ \\
\hline No & $82(13.4)$ & $529(86.6)$ & 1 \\
\hline
\end{tabular}


Table 3. Child health and demographic determinants in relation to childhood diarrhea morbidity among graduated household in rural area of Shebedino district, Southern Ethiopia, 2013.

\begin{tabular}{|c|c|c|c|}
\hline \multirow{2}{*}{ Variables } & \multicolumn{2}{|c|}{ Childhood diarrhea N (\%) } & \multirow{2}{*}{ COR ( 95\% CI) } \\
\hline & Yes & No & \\
\hline \multicolumn{4}{|l|}{ Age of index child } \\
\hline $0-5 \mathrm{~m}$ & $14(14.7)$ & $81(85.3)$ & $0.627(.338-1.162)$ \\
\hline $6-11 \mathrm{~m}$ & $12(11.8)$ & $90(88.2)$ & $0.484(.253-.926)^{* *}$ \\
\hline $12-23 m$ & $42(22.3)$ & $146(77.7)$ & $1.043(.685-1.589)$ \\
\hline 24 and above & $83(21.6)$ & $301(78.4)$ & 1 \\
\hline \multicolumn{4}{|l|}{ Sex of index child } \\
\hline Male & $83(21)$ & $312(79)$ & $1.197(.837-1.71)$ \\
\hline Female & $68(18.2)$ & $306(81.8)$ & 1 \\
\hline \multicolumn{4}{|c|}{ Place where child borne } \\
\hline Health institution & $46(15.3)$ & $254(84.7)$ & 1 \\
\hline At home & $105(22.4)$ & $364(77.6)$ & $1.593(1.087-2.33)$ \\
\hline \multicolumn{4}{|l|}{ Birth order } \\
\hline First & $30(20)$ & $120(80)$ & 1 \\
\hline Second & $44(18.6)$ & 193(81.4) & $0.912(.544-1.53)$ \\
\hline Third & $30(19.7)$ & $122(80.3)$ & $0.984(.559-1.731)$ \\
\hline Fourth and above & $47(20.4)$ & $183(79.6)$ & $1.027(.615-1.72)$ \\
\hline \multicolumn{4}{|c|}{ Duration of breast feed } \\
\hline$<5$ month & $18(15.0)$ & $102(85)$ & $0.664(.376-1.172)$ \\
\hline 5-11month & $17(16.2)$ & $88(83.8)$ & $0.727(.405-1.304)$ \\
\hline 12-23 month & $49(21.8)$ & $176(78.2)$ & $1.047(.691-1.587)$ \\
\hline$>=24$ month & $67(21)$ & $252(79)$ & 1 \\
\hline \multicolumn{4}{|l|}{ Nutritional status } \\
\hline Normal & 74(13.6) & $472(86.4)$ & 1 \\
\hline Undernourished & $77(34.5)$ & $146(65.5)$ & $3.364(2.326-4.867)$ \\
\hline \multicolumn{4}{|c|}{ History of measles vaccination } \\
\hline Yes & $133(21.4)$ & 488(78.6) & $2.544(.762-8.496)$ \\
\hline No & $3(9.7)$ & $28(90.3)$ & 1 \\
\hline
\end{tabular}

$* * \mathrm{P}$-value $<0.05$

Table 4. Model describing hierarchical logistic regression analysis of determinant of childhood diarrhea among graduated household in rural area of Shebedino district, 2013

\begin{tabular}{ccc}
\hline & Model X2(p- value) & $\begin{array}{c}\text { Hosmer-Lemeshow goodness } \\
\text { of-fit-test (p-value) }\end{array}$ \\
\hline Model 1 & $60.39(.0001)$ & 0.032 \\
Model 2 & $90.04(.0001)$ & 0.314 \\
Model 3 & $201.0(.0001)$ & 0.845 \\
\hline
\end{tabular}

\subsection{Determinants of Childhood Diarrhea: Multivariable Result}

\subsubsection{Model Descriptions: Group Analysis}

Socio-demographic factors were not significantly associated with the prevalence of childhood diarrhea; however, in combination with environmental factors, the socio-demographic factors significantly affect the prevalence of childhood diarrhea.

Behavioral factors interact with socio-demographic and environmental factors explain more about the prevalence of childhood diarrhea.

\subsubsection{Individual Analysis}

Accordingly the household graduated before 2003 EC had two times higher odd of childhood diarrhea than household who were graduated after 2003 EC [AOR: 1.83, 95\% CI :( $1.16,2.89)]$. Odds of having diarrhea in children who lived in households where there two or more children were about two times higher than the odds in children who lived in households where there was only one child [AOR: 1.96, 95\% CI: $(1.23,3.12)]$.

Mean per capita water consumption per day remained significant in the final model from all selected environmental variables tested in the second step of analysis, thus when one liter increase of water per household decrease diarrhea prevalence by $2.7 \%$ [AOR:0.98, 95\% CI: (0.96, 0.99)]

Maternal diarrhea morbidity, the mode of feeding by cup and nutritional status where remained significant at final model. The odd of having diarrhea in children who were born from mother with history of diarrhea was six times higher than that of children who were born from diarrhea free mother[AOR: 5.76, 95\% CI: $(3.50,9.47)$ ]. The odd of 
childhood diarrhea in children who was not feed by cup were two times higher than the odd of childhood diarrhea in children who was feed by cup [AOR: 2.13, 95\%CI:(1.09,
4.13)]. The odd of having diarrhea among under nourished children was four times higher than the odd of diarrhea in normal children [AOR: 4.06, 95\% CI :(2.54, 6.50)].

Table 5. Summary of the hierarchical logistic regression analysis of determinant on the prevalence of childhood diarrhea, in rural area of Shebedino district, Southern Ethiopia, 2013

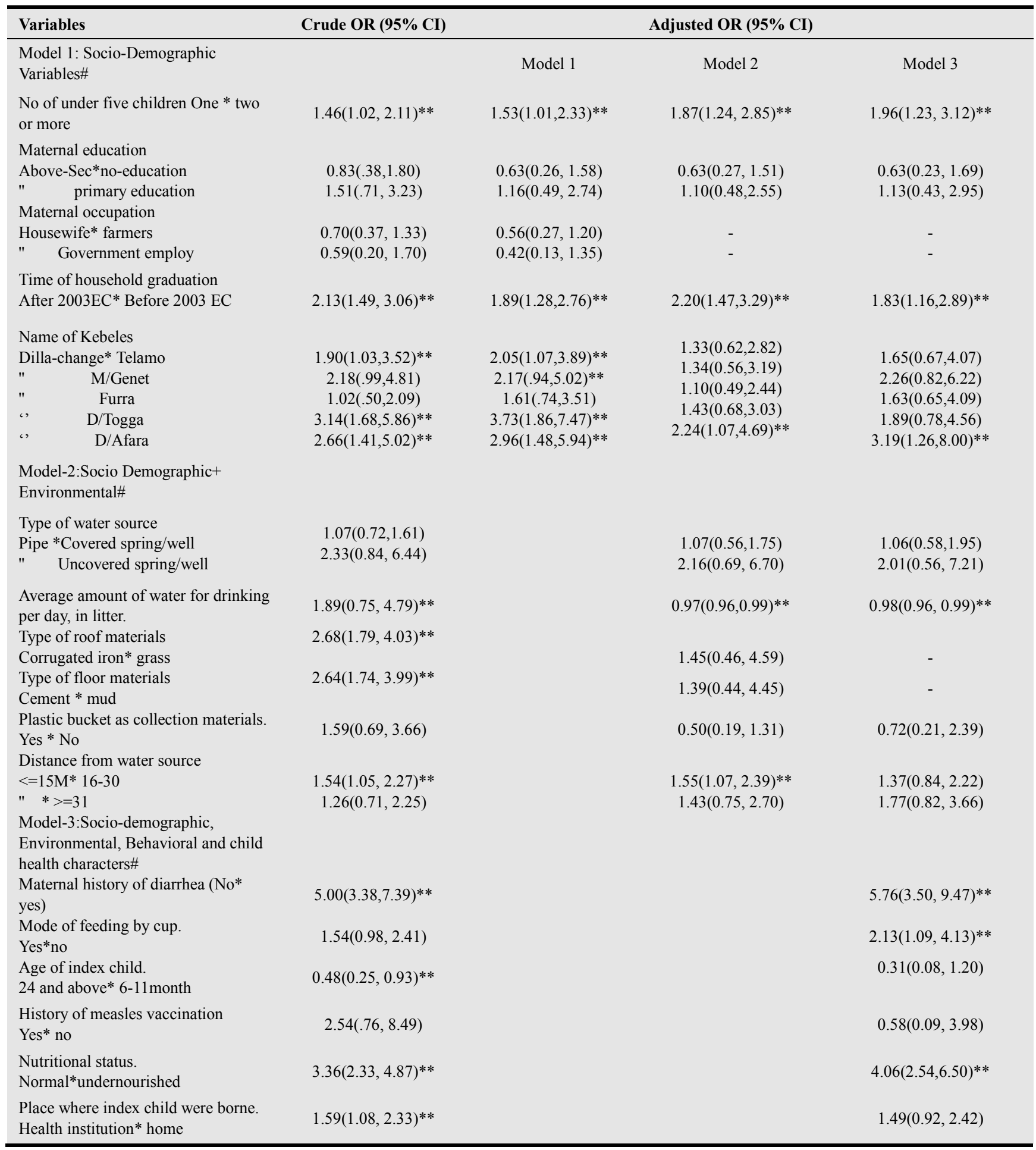

Notes: \# only variables reached p-value less than 0.3 were kept in the subsequent analyses, and displayed in the table.* Reference group.

\section{Discussion}

The finding of this study revealed that the prevalence of childhood diarrhea among graduated household in the district was 19.6 percent, this is consistent with findings in the Mecha district of west Gojjam of Ethiopia (18\%), and 
recent EDHS report of SNNPR (16.4\%) and Nigerian study $(16.9 \%)$. This is due to conformity in the method of data collection, which collected the same information from one visit using a two-week recall period (11-13). But inconsistent with the study done in Hullet Eju Enessie district $(6.5 \%)$, and the study done in Nekemte Town $(28.5 \%)(14,15)$. The lower prevalence in Hullet Eju Enessie district might be due to household complies with HEP packages and due to season of data collection which is dry season, when diarrhea prevalence is low. But high prevalence in Nekemte town was attributable to lack of diarrhea intervention program like urban health extension program during this study was conducted(16)

But inconsistent with the study done in Hullet Eju Enessie district $(6.5 \%)$, and study in Nekemte Town $(28.5 \%)(14,15)$. The lower prevalence in Hullet Eju Enessie district might be due to household complies with HEP packages and due to season of data collection which is dry season, when diarrhea prevalence is low. But high prevalence in Nekemte town was attributable to lack of diarrhea intervention program like urban health extension program during this study was conducted

Time of household graduation and number of under-five children were persisted their significance in the final model. Studies showed that the number of children in a household had impacts on the occurrence of diarrhea in children $(7,12)$. As the number of children in a family becomes larger, there may be crowding which deteriorate the sanitation, which in turn increases the chance of contact with different pathogens related with diarrhea. In addition they are competed for mother's time, attention and other resources $(12,17,18)$

This was in line with the study done in Butajira, Southern Ethiopia, but inconsistent with the study done in Thailand, according to this study the prevalence of childhood diarrhea among household with one child were higher than two or more $(7,19)$.

Even after controlling for all environmental, behavioral and other socio-demographic variables considered in the final model, the time of household graduation were significant, thus the odd of having diarrhea among household who were graduated before 2003 EC were two times more than the odd of having diarrhea among household who were graduated after 2003 EC. This might due to decreased strengths of training and less follow up from the health extension worker for the former graduated household and households also fail to conform with the HEP package that concerned with family health, child care practice and infectious disease prevention and control, particularly for diarrheal disease when time progress.

From all the environmental variables considered in this study, only mean per capita water consumption per household remained significant after controlling for socio demographic, behavioral and other environmental variables. This might be due to adequate amount of water for domestic and hygienic purposes, which in turn decrease the prevalence of diarrhea(20-22).
The lack of association between type of water source and latrine availability versus diarrheal morbidity may be explained by no great differences exist in the sample graduated households with respect to the use of protected water source and latrine availability as well utilizations. From the graduated households studied 100\% had latrine and $97.8 \%$ use protected water sources. In addition to this, type of water source provides little information about water quality or protection against diarrheal infection.

It was well documented that maternal childcare, child demographic and health characteristics have important impacts on the occurrence of childhood diarrhea $(16,19)$. This study showed maternal diarrheal morbidity, found to be significant predictors of diarrheal prevalence in children. The six-fold increase in the odds of getting diarrhea in children whose mothers had diarrhea may be explained by the fact that maternal morbidity may be considered as a feature of disease exposure in a family. This is because mothers are food handlers of the family, and also they are usual childcare providers. Moreover, the care of the child may be compromised if the mother herself is sick; Mother's exposure to diarrhea may also indicate poor hygienic practice in the household that results in disease incidence for the child/children. Similar finding was observed in other study in Ethiopia, where maternal diarrheal morbidity was associated with a five -fold increase in the odds for diarrheal disease in children(7).

Being the child of mother who feed by cup were preventive against childhood diarrhea than that of not feed by cup, this might due to less contamination with maternal hand at the time of feeding. This is evidenced by the study done in Thailand that mother who feed their child by cup can decrease the diarrhea illness (16). Ethiopian study coudn't showed this(19).

A nutritional statue of the child was determinant of childhood diarrhea. Under nourished child was four times more likely to develop childhood diarrhea than that of well nourished child. This might be due to poor feeding practice for child, co-morbidity and lack of fortified food and micronutrient supplementation. The finding was in line with study done in Ethiopia(Dabat district) and Peru, south America but inconsistent with study done in India, that nutritional status was not statistically associated with occurrence of childhood diarrheal illness, rather with duration of diarrheal illness(23-25).

\section{Limitation of the Study}

Owing to the community-based study design, and the use of hierarchical logistic model, we can assume that the findings could take greater proportion of the subjects and consistency in response. However, it shares the drawbacks of similar cross-sectional studies. The study was conducted in the early rainy season (April) and probably it might have overestimate diarrhea prevalence as compared to dry rainy season, and a limitation to the generalizability of the result. 


\section{Conclusion}

This study showed the prevalence of childhood diarrhea is quite high $(19.6 \%)$, and time of household graduation, number of under-five children, mean water consumption per households, maternal history of diarrhea and nutritional status were possible determinants of the occurrences of childhood diarrhea. So health extension worker should give health education to mothers on behavioral change regarding care of their child during they are ill and the governments should strengthen sustainability of household health extension program by giving regular training and warm up at list every two years for graduated households and the program should focus on mothers, since maternal problem is a problem of the family. In addition adequate water supply and nutritional care should get emphasis so as to control and prevents diarrhea morbidity among under five children.

\section{Acknowledgements}

We acknowledge the financial and technical support provided by College of Medicine and Health Sciences, University of Gondar. The support obtained by district health offices, data collectors and all the study participants who participated in the study were highly acknowledged.

\section{Authors' Contributions}

AT: initiation of the study, design, implementation, analysis and writing. AA: design, implementation, analysis and writing. MY: implementation and co-writing. All authors read and approved the final manuscript.

\section{Competing Interest}

The author declare that there is no competing interest

\section{References}

[1] Gerald T. Keusch OF, Alok Bhargava, et al. Diarrheal disease: DT. Breman JG MA, et al, editor. Disease control priorities in developing countries. 2nd edition, ed. washington World bank; 2006. p. 371- 85 .

[2] UNICEF. Level and trends in child mortality: New york: 2011.

[3] Ethiopia Demographic and health survey (EDHS), Central Statistics Authority \& ORC Marco. Addis Ababa, Ethiopia and Calverton, Maryland, USA: 2011.

[4] Regassa G, BW, Deboch B, Belachew T. Environmental determinant of diarrhea among under five children in Nekemte Town, Western Ethiopia. Ethiop J Health Sci. November 2007;18(2):40-5. Epub July 2008.

[5] Dessalegn M, KA, Tefera W. Predictors of under-five childhood diarrhea at Mecha District, West Gojam, Ethiopia. Ethiop J Health Dev. 2009;25(3):193-9. Epub 2011.
[6] Bethany Caruso RS, and Juan S. Leon. Maternal behavior and experience, care access, and agency as determinants of child diarrhea in Bolivia,. Rev Panam Salud. 2010 December; 28(6): 10 .

[7] Mulugeta T. Socio-economic, environmental, and behavioral factors associated with the occurrence of diarrheal disease among under-five children, Meskana Mareko Woreda, Southern Ethiopia [MPH thesis]: AAU; 2003.

[8] Kloos H. Primary health care in Ethiopia under three political systems: community participation in a war-torn society. Social science \& medicine (1982). 1998 Feb-Mar;46(4-5):505-22. PubMed PMID: 9460830. Epub 1998/02/14. eng.

[9] Kedir B, Nejmudin CHH, Feng Zhao et al. Health extension workers in Ethiopia: Improved access and coverage for the rural poor. 2011. p. 434-43.

[10] Hailom B. Ethiopia's Health extension program: Improving health through Community Involvement. Medicc Review. july $1011 ; 13(3)$.

[11] Dessalegn Muluken KA, Tefera Worku. Predictors of under-five childhood diarrhea at Mecha District, West Gojam, Ethiopia. Ethiop J Health Dev. 2009;25(3):193-9. Epub 2011.

[12] Calitus Wilunda AP. Factors associated with diarrhea among children less than 5 years old in Thailand: A Secondary analysis of thailand multiple indicator cluster survey 2006, J Health Res 2006;23(suppl ):5. Epub 2009.

[13] Olufunke F OO. Prevalence and Treatment of Childhood Diarrhea among Nigerian Ethnic Groups. The Nigerian Journal of Sociology and Anthropology 2003;Vol. 7:5. Epub 2008.

[14] Regassa Girma BW, Deboch Bishaw, Belachew Tefera. Environmental Determinant of Diarrhea among under five children in Nekemte Town, Western Ethiopia. Ethiop J Health Sci. November 2007;18(2):40-5. Epub July 2008.

[15] Andualem Anteneh Ak. Assessment of the impact of latrine utilization on diarrhoeal Diseases in the rural community of Hulet Ejju Enessie Woreda, East Gojjam Zone, Amhara Region, Ethiop. J Health Dev. 2006;24(2). Epub 2010.

[16] USAID, End of Project Evaluation For the Urban Health Extension Program. Addis Abeba: 2012.

[17] Woldemichael G. diarrheal morbidity among young children in Eritrea: Environmental and socioeconomic determinants. J Health Popul Nutr. 2001 Jun;19(2): 83-90.

[18] Oni, GA. infant feeding practices, socioeconomic conditions and diarrheal disease in a traditional area of urban Ilorin, Nigeria. Est. Afr. Med. J. 1996; 73(5): 283-288.

[19] Calitus Wilunda AP. Factors Associated with Diarrhea among Children Less than 5 Years old in Thailand: A Secondary Analysis OF Thailand Multiple Indicator Cluster survey 2006,. J Health Res 2006;23(suppl ):5. Epub 2009.

[20] WHO. The Hygiene Improvement Framework, A Comprehensive Approach for Preventing Childhood Diarrhea. Geneva, Swizerland Available from: www.ehproject.org.

[21] Program. Gd. Water, Sanitation \& Hygiene. August 2012; Available from: www.gatesfoundation. org. 
[22] Behailu Silesh RG, Mamo Dereje, Dimtse Desta, and Peter Newborne, Promoting Sanitation and Hygiene to rural households in SNNPR, Ethiopia: Experiences of Health Extension Workers and Community Health Promoters. 2010.

[23] Anand K, Sundaram KR, Lobo J, Kapoor SK. Are diarrheal incidence and malnutrition related in under five children? A longitudinal study in an area of poor sanitary conditions. Indian pediatrics. 1994 Aug;31(8):943-8. PubMed PMID: 7883347. Epub 1994/08/01. eng.
[24] Checkley W, Gilman RH, Black RE, Lescano AG, Cabrera L, Taylor DN, et al. Effects of nutritional status on diarrhea in Peruvian children. The Journal of pediatrics. 2002 Feb;140(2):210-8. PubMed PMID: 11865273. Epub 2002/02/28. eng.

[25] Destaw B. Prevalence and associated factors for diarrhoeal disease among under five children in dabat district, North west Ethiopia (Gondar Universty Master thesis). 2009. 